\title{
Parastyle in Primary Molars: A Rare Case Series
}

\author{
Archna Agnihotri ${ }^{1}$, Rosy Arora ${ }^{2}$, Urvashi Sharma ${ }^{3}$
}

\begin{abstract}
Human teeth manifest high degree of diversity in both primary and permanent dentition. Paramolar tubercle (parastyle) is one of the rare morphological variations particularly if present in primary dentition with a prevalence ranging from $0.3-1.5 \%{ }^{1}$ These deviations are thought to be the remnants of buccal cingulum in lower primates. Morphological aberrations of such kind give an insight to development and evolution of dentition. However, these can also predispose to a variety of clinical problems. A complete understanding of dental anatomy and its variations is therefore imperative for successful completion of dental procedures. These aberrations also hold a great importance in forensic field such as in the identification of criminals or victims during mass causalities. This case series presents a rare finding of occurrence of paramolar tubercles in primary molars in four North Indian children and presence of a similar parastyle in one of the siblings. This paper is an attempt to educate the clinicians towards the existence of such a trait and its clinical significance so that it can be studied in larger numbers.

Keywords: Morphology, Parastyle, Paramolar tubercle, Parastyle, Primary molars.

Journal of South Asian Association of Pediatric Dentistry (2021): 10.5005/jp-journals-10077-3100
\end{abstract}

\section{INTRODUCTION}

Human teeth exhibit a large number of morphological variations both in primary and permanent dentition. These variations could be in the crown in the form of anomalous cusps or number of roots. Over more than hundred morphological dental traits have been observed in human dentition. Of all these non-metric dental traits that have been studied as an ethnic marker of the population are the ones mainly placed on the incisor crown and molars of both the dentition; the most common of these being the parastyle and protostyle. $^{2-4}$

Presence of an accessory cusp on the buccal surface of the mesiobuccal cusp of maxillary molars is referred to as parastyle, paramolar cusp or a paramolar tubercle. The etiology of occurrence of the additional cusp formation or deviated morphology is multifactorial and is probably a result of overactivity of the dental lamina..$^{5}$ According to the tritubercular theory, an enamel collar circumscribes at the level of gingival third in crowns of the teeth that leads to the formation of cingulate in anterior teeth, protostylid or tubercles on lower molars and parastylid on upper molars. ${ }^{6}$ Bolk was the first one to describe these anatomical deviations ${ }^{7}$ and were referred to as protostylid and parastylid in the paleontologic nomenclature by Dahlberg in $1945 .{ }^{8}$ Paramolar tubercle is relatively a rare entity specifically in primary dentition and there are few studies available on its prevalence. In one of the studies, Kustaloug reported their prevalence being relatively lower in maxillary first molars $(0-0.1 \%)$ followed by $(0.4-2.8 \%)$ in second and $(0-4.7 \%)$ in third molars and predisposition to bilateral occurrence in deciduous dentition and unilateral occurrence in permanent dentition. . $^{1,11,12}$

He further noted higher incidence in South-western Indians as compared to other populations like North-western Indians, Negros, Whites, Melanesians, Filipinos, Hawaiians, Kish and Peruvians. ${ }^{9}$ Turner and Katich classified paramolar tubercle for permanent molars into six types based on its appearance (Table 1). ${ }^{10}$ Scriven et al. described the frequency of occurrence of paramolar tubercles as $0.3-1.5 \%$ and also observed the degree of expression of the trait in six different ethnic groups and twin pairs. ${ }^{1}$ Nagaveni et al. reported more than eight cases of paramolars tubercles in the maxillary primary first molars in Indian patients and proposed a

\begin{abstract}
${ }^{1-3}$ Department of Pedodontics, Dr. HSJIDS, Panjab University, Chandigarh, India
\end{abstract}

Corresponding Author: Archna Agnihotri, Department of Pedodontics, Dr. HSJIDS, Panjab University, Chandigarh, India, Phone: +91 9876075774, e-mail: archna.agnihotri@gmail.com

How to cite this article: Agnihotri A, Arora R, Sharma U. Parastyle in Primary Molars: A Rare Case Series. J South Asian Assoc Pediatr Dent 2021;4(3):208-211.

Source of support: Nil

Conflict of interest: None

new classification system for better grading of paramolar tubercles specifically for primary molars based on the classification given by Turner and Katich (Table 2). ${ }^{13}$ Kazak et al. used cone-beam computed tomography (CBCT) for the evaluation of paramolar tubercle in permanent molars in turkish population and found the existence of independent root canals in paramolar tubercles. ${ }^{13}$ These morphological variations and complex internal anatomy in parastyle make it pernitent for the clinicians to be aware of such uncommon deviations. The present case series aims to report the presence of parastyle in deciduous molars in four North Indian children and its occurrence in one of the siblings.

\section{Case 1}

A six-year-old North Indian girl reported with her elder sibling for routine dental checkup to the Department of Pediatric Dentistry. Her medical and dental histories were non-significant and there was no sign of any systemic disease or syndrome. There was no reported history of orofacial trauma. Extraoral examination revealed no abnormalities. Intra oral examination revealed mixed dentition with no softtissue abnormalities. There were mild stains present and no evidence of caries except a restoration in 53. Morphological alterations were found to be present bilaterally on mesiobuccal cusps in maxillary primary first molars. The primary right maxillary first molar (54) showed a cusp-like projection which was conical in shape with its base near the gingival margin and its apex pointing occlusally, the cusp was separated by a deep developmental groove.

(c) The Author(s). 2021 Open Access This article is distributed under the terms of the Creative Commons Attribution 4.0 International License (https://creativecommons. org/licenses/by-nc/4.0/), which permits unrestricted use, distribution, and non-commercial reproduction in any medium, provided you give appropriate credit to the original author(s) and the source, provide a link to the Creative Commons license, and indicate if changes were made. The Creative Commons Public Domain Dedication waiver (http://creativecommons.org/publicdomain/zero/1.0/) applies to the data made available in this article, unless otherwise stated. 
Mesiodistally, it was centered on the mesiobuccal cusp and $2 \mathrm{~mm}$ short of the cusp tip cervico-occlusally. There was no evidence of caries. The left maxillary first molar (64) presented with a bulge that was smooth and blended into the buccal surface with respect to the mesiobuccal cusp (Fig. 1). Based on the clinical appearance and classification given by Nagaveni et al. for paramolar tubercles a diagnosis of type-4 paramolar tubercle was made for the projection on right maxillary first primary molar and type-1 paramolar tubercle for left maxillary first primary molar (Fig. 2). The fissure sealant was placed on paramolar tubercle on right first maxillary molar. The paramolar in 64 blended well into the buccal surface and in the absence of any fissure associated with tubercle, no treatment was done for 64. Oral hygiene instructions were given and was advised regular follow up.

\section{Case 2}

Routine dental examination of her eight-year-old elder sibling (Case 1) who reported along also had no contributory dental and medical history. Extraoral examination revealed no abnormalities.

Table 1: Varied clinical presentation of parastyle/paramolar tubercle in permanent molars $^{13}$

\begin{tabular}{|c|c|}
\hline Grade & Description \\
\hline I & Buccal surfaces of cusp 2 and 3 are smooth \\
\hline II & $\begin{array}{l}\text { A pit is present in or near the buccal groove between } \\
\text { cusps } 2 \text { and } 3\end{array}$ \\
\hline III & Small cusp present with attached apex, usually on cusp 2 \\
\hline IV & $\begin{array}{l}\text { Medium-sized cusp present with free apex anywhere on } \\
\text { the buccal surface }\end{array}$ \\
\hline V & $\begin{array}{l}\text { Large cusp present with free apex anywhere on the buc- } \\
\text { cal surface }\end{array}$ \\
\hline $\mathrm{VI}$ & $\begin{array}{l}\text { Very large cusp present with free apex anywhere on the } \\
\text { buccal surface }\end{array}$ \\
\hline VII & $\begin{array}{l}\text { Free peg-shaped crown is present attached to the third } \\
\text { molar root }\end{array}$ \\
\hline
\end{tabular}

Table 2: Classification system for grading paramolar tubercle in the primary molars $^{11}$

\begin{tabular}{ll}
\hline Type & Description \\
\hline I & Refers to a bulge that is smooth and blending into the \\
buccal surface with respect to the mesiobuccal cusp and \\
not demarcated by a groove \\
Refers to a morphologically well-delineated \\
prominentbulge that projects from the buccal surface of a \\
primary molar and extends at least half the distance from \\
the cemento-enamel junction to the middle third and is not \\
separated by a well-demarcated groove \\
Refers to a prominent additional cusp-like structure \\
extending less than half the distance from the \\
cementoenamel junction to the occlusal table and stands \\
away from the buccal surface by a well-demarcated \\
developmental groove \\
Refers to a distinct cusp-like structure extending more than \\
half the distance from the cementoenamel junction to the \\
occlusal table and stands away from the buccal surface by a \\
well-demarcated developmental groove \\
Refers to a prominent additional cusp-like structure \\
extending from the cervical third and almost reaching the \\
occlusal table, and stands away from the buccal surface by a \\
well-demarcated developmental groove
\end{tabular}

Intraoral examination revealed mixed dentition, mild stains and class II restoration in 55. Primary maxillary left first molar (64) presented with a similar parastyle on the paracone cusp. It was conical in shape with its base below the gingival margin and its apex oriented occlusally and the cusp was separated by a deep developmental groove. It was located in the centre of paracone cusp and $3 \mathrm{~mm}$ short of the tip of the mesiobuccal cusp. As per scale given by Nagaveni et al. it was graded as type-4 paramolar tubercle (Fig. 3). All other teeth revealed no abnormalities. The fissure

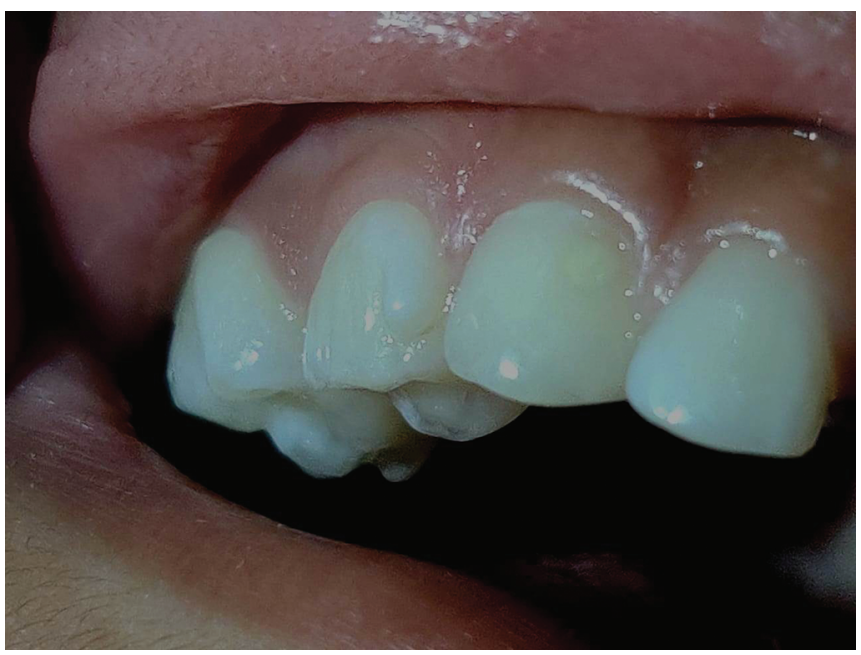

Fig. 1: Primary maxillary right second molar with type-4 paramolar cusp

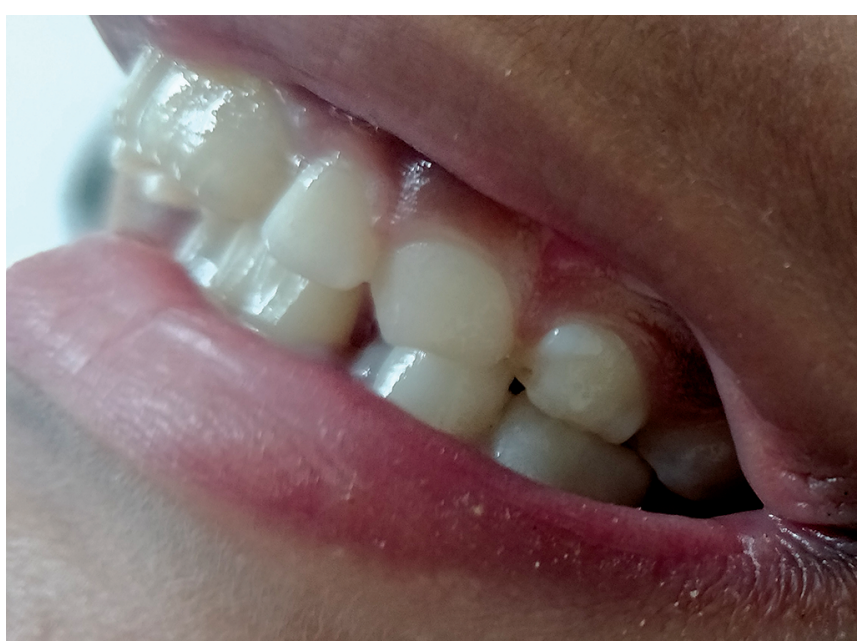

Fig. 2: Primary maxillary left first molar with type-1 paramolar cusp

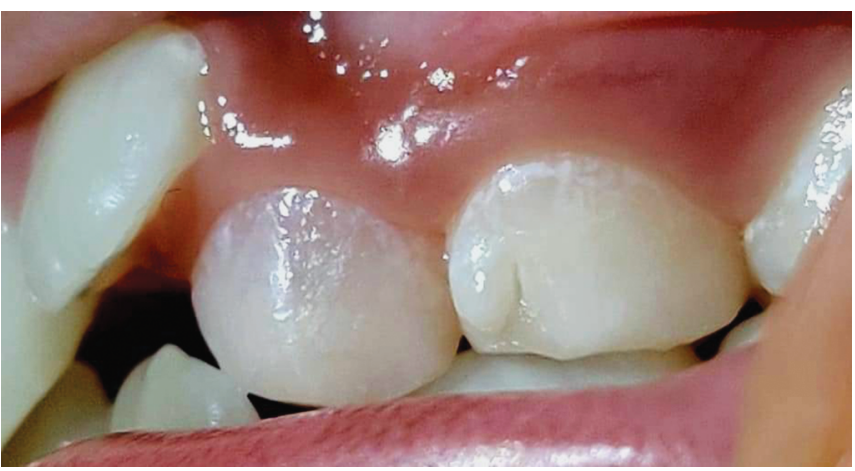

Fig. 3: Primary maxillary left first molar with type-4 paramolar cusp 
associated with the parastyle was sealed with the fissure sealant and patient was advised to stay on regular recall appointments.

\section{Case 3}

A ten-year-old girl child reported for routine dental examination. Her medical and dental histories were non-significant and there was no sign of any systemic disease or syndrome. There was no reported history of orofacial trauma. Extraoral examination revealed no abnormalities. Intra oral examination revealed mixed dentition with no soft-tissue abnormalities.

The primary right maxillary first molar (54) showed a cusp like projection which was conical in shape with its base near the gingival margin and its apex pointing occlusally, centered occluso-gingivally separated by a shallow groove with attached apex and $3 \mathrm{~mm}$ short of mesial marginal ridge on the mesial third of mesiobuccal cusp (Fig. 4). Based on the clinical appearance and classification given by Nagaveni et al., diagnosis of type-3 paramolar tubercle was made. The fissure was sealed with the fissure sealant, oral hygiene instructions were given and was advised regular follow-up.

\section{Case 4}

An eight-year-old male child reported with the chief complaint of blackish discoloration in right upper back teeth. His medical and dental histories were nonsignificant and there was no sign of any systemic disease or syndrome. There was no reported history of orofacial trauma. Extraoral examination revealed no abnormalities. Intraoral examination revealed mixed dentition with proclined anteriors and no soft-tissue abnormalities. The primary right maxillary first molar (54) showed a cusp like projection which was conical in shape with its base near the gingival margin and its apex pointing occlusally, the cusp was separated by a deep developmental groove. Mesiodistally, it was centered in the mesiobuccal cusp and $2 \mathrm{~mm}$ short of the cusp tip cervico-occlusally (Fig. 5). As per scale given by Nagaveni et al., it was graded as type-3 paramolar tubercle.

There were mild stains present and proximal cavitation wrt 54. IOPA for 54 showed dentinal caries which was restored with composite. The fissure was sealed with the fissure sealant and patient was advised to stay on regular recall appointments. Appropriate consent was taken from all the parents for the use of pictures and information in the literature.

Summary of patients with paramolar tubercle:

\begin{tabular}{lllll}
\hline $\begin{array}{l}\text { Case } \\
\text { no. }\end{array}$ & Age/sex/Race & $\begin{array}{l}\text { Associated } \\
\text { tooth }\end{array}$ & Grading & $\begin{array}{l}\text { Treatment } \\
\text { provided }\end{array}$ \\
\hline 1 & 6 years/F & 54,64 & Type 4/Type1 & $\begin{array}{l}\text { Prophylactic } \\
\text { sealing with } \\
\text { sealants for } \\
54\end{array}$ \\
2 & 8 years/F & 64 & Type 4 & $\begin{array}{l}\text { Prophylactic } \\
\text { sealing with } \\
\text { sealants }\end{array}$ \\
3 & 10 years/F & 54 & Type 4 & $\begin{array}{l}\text { Prophylactic } \\
\text { sealing with } \\
\text { sealants } \\
\text { Prophylactic } \\
\text { sealing with } \\
\text { sealants }\end{array}$ \\
\hline & & & Type 3 & \\
\hline
\end{tabular}

\section{Discussion}

Parastyle/paramolar tubercle or paramolar cusp is a nonmetric dental trait considered as a cingulum expression presenting on the buccal surface of paracone cusp of the upper molars and thought to be representing the remnants of the cingulum of mammals and lower primates. $^{13}$

Nonmetric dental traits are rare morphological variations that provide an insight into genetics, dental evolution and individual's forensic identification. ${ }^{14}$ The presence of similar parastyle in siblings in the case series further substantiates the hereditary component. Most lines of evidence (For example, zygosity diagnosis in twins, familial correlations, population variation) indicate genes are the major controlling factor in the crown and root trait development. Trait expression is however is also affected sometimes by the environmental factors. The dentition shows the properties of a complex adaptive system and is characterized by bilaterality and mirror imagery between both sides of the jaw in crown size and morphological trait expression so bilateral occurrences are found to be more common. ${ }^{15}$ The clinical implications of these structures make it essential to timely diagnose and provide a treatment plan if required. The anomalous tooth structures increase the predisposition to localized gingivitis, periodontitis due to increased plaque accumulation.

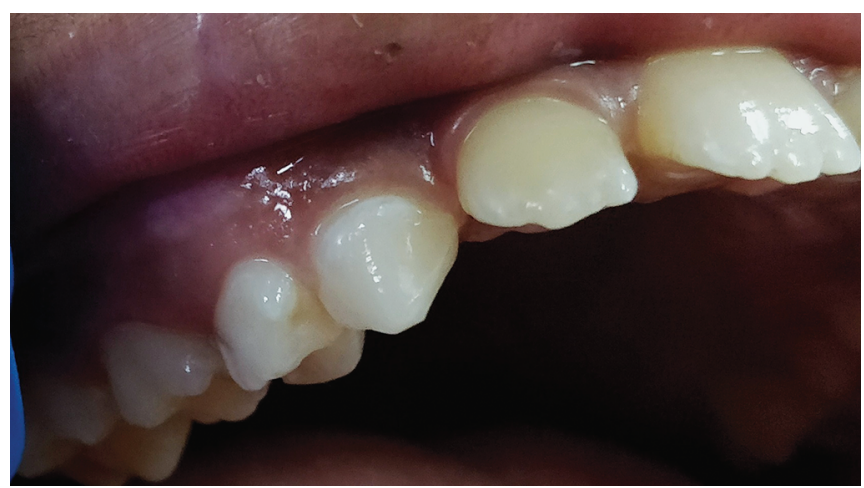

Fig. 4: Primary maxillary right first molar with type-3 paramolar cusp

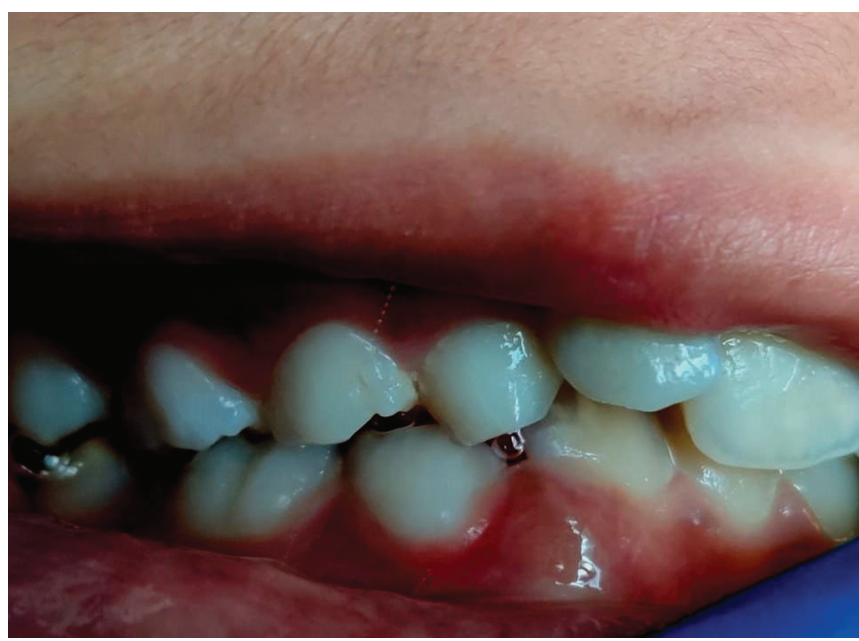

Fig. 5: Primary maxillary right first molar with type-3 parmolar cusp 
Fissure between accessory free cusp tip and tooth surface is susceptible to dental caries and may result in pulpal involvement, difficulty in root canal treatment and possibility of failure. In cases requiring endodontic treatment clinicians should be aware of the unpredictable complex internal anatomy in these cases. These structures can interfere during placement of orthodontic bands, brackets, and cementation of stainless steels crowns.

Frictional keratosis may also result due to impingement from extra sharp cusps. Hence, prophylactic fissure sealing can prevent endodontic therapy following carious involvement. If the fissure is maintainable no treatment is usually required.

Enameloplasty may be considered if they interfere with cementation of brackets and correct alignment of orthodontic archwires. Due to abnormal internal configuration of parastyle such as presence of independent root canal within the paramolar tubercle or its communication with the main root canal may present challenges during treatment; detailed examination with modern diagnostic aids such as CBCT may be utilized before undertaking any treatment. ${ }^{12}$ Timely diagnosis, prophylactic sealing along with oral hygiene maintenance and recall can help prevent complications and plan the treatment accordingly. In this case series paramolar tubercles were found in primary dentition in North Indians which has never been documented in literature; as available studies have shown higher occurrence in Southwestern Indians making this case series even rarer.

\section{Conclusion}

Paramolar tubercle is a rare anatomical variation and due to its low incidence and reporting their occurrence in primary dentition is often missed. Clinicians should be aware of these aberrations and their complexities for diagnosis and prevention of complications arising due to presence of such structures. In the present case series paramolar with fissures were sealed prophylactically and patients were made aware of their presence and necessary oral hygiene instructions to be followed to improve the prognosis of the teeth.

\section{References}

1. Scriven G, Roger J, Brook A et al. Frequency of occurrence and degree of expression of the parastyle in several modern human populations. Dent Anthropol J 2018;31(1):3-9. DOI: 10.26575/daj. v31i1.4
2. Scott GC, Turner 2nd CG. In: The anthropology of modern human teeth: dental morphology and its variation in recent human populations. London: Cambridge University Press; 1997.

3. Hillson S. In: Dental anthropology. London: Cambridge University Press; 1996.

4. Rodríguez JV. In: Teeth and human diversity: progress of dental anthropology. Bogotá: National University of Colombia; 2003.

5. Omal PM, Philipose L, Mathew AL, et al. Parastyle in a permanent maxillary first molar tooth: a rare entity. J Indian Acad Oral Med Radiol 2013;25:137-140.

6. Butler PM. Some functional aspects of molar evolution. Evolution 1972;26(3):474-483. DOI: 10.1111/j.1558-5646.1972.tb01951.x

7. Bolk L. Problem of human dentition. Am J Anat 1916;19:91-148. DOI: 10.1002/aja.1000190106

8. Dahlberg AA. The paramolar tubercle (Bolk). Am J Phys Anthropol 1945;3:97-103. DOI: 10.1002/ajpa.1330030119

9. Kustaloug OA. Paramolar structures of the upper dentition. J Dent Res 1962;41:75-83. DOI: 10.1177/00220345620410015001

10. Nagaveni NB, Umashankara KV, Radhika NB, et al. Paramolar tubercle" in the primary dentition: Cases reports and literature review. Inter J Dent Anthropol 2009;14:12-18. DOI:10.4103/2231-6027.151615

11. Nagaveni NB, Umashankara KV, Poornima P, et al. Paramolar tubercle (Parastyle) in primary molars of Davangere (India) children: a retrospective study. Int J Oral Health Sci 2014;4:18-22. DOI: 10.4103/2231-6027.151615

12. Colakoglu G, Kaya Buyukbayram I, Elcin MA, et al. Evaluation of the internal anatomy of paramolar tubercles using cone-beam computed tomography. Surg Radiol Anat 2020 Jan;42(1):15-21. DOI: 10.1007/s00276-019-02361-1

13. Turner 2nd CG, Nichol CR, Richard Scott G. Scoring procedures for key morphological traits of the permanent dentition: the Arizona State University dental anthropology system. Adv Dent Anthropol 1991;3:13-31.

14. Chowdhary Z, Gupta D, Mohan R, et al. Parastyle cusp: a rare morphologic variant of maxillary second molars. J Forensic Dent Sci 2018;10(2):111-115. DOI: 10.4103/jfo.jfds_9_17

15. Scott GR, Turner 2nd CG, Townsend GC, et al. Morphological trait expression. In: The anthropology of modern human teeth: dental morphology and its variation in recent and fossil Homo sapiens. Cambridge University Press; 2018: pp. 129-65. 